\title{
Vulnerability Assessment of Forest Ecosystem to Climate Change in Korea Using MC1 Model
}

\author{
Sungho Choi*1, Woo-Kyun Lee*1, Hanbin Kwak*1, So-Ra Kim*1, Seongjin Yoo*1, \\ Hyun-Ah Choi ${ }^{* 2}$, Sunmin Park ${ }^{* 2}$ and Jong-Hwan Lim*3
}

\begin{abstract}
The objective of this study was to assess the vulnerability of forest ecosystem to climate change in Korea using MAPSS-CENTURY (MC1) model, one of Dynamic Global Vegetation Models (DGVMs). Also, it was to suggest selected and concentrated adaptation strategies for local government on the basis of this assessment. For the MC1 simulation of past years (1971-2000), the climatic data was prepared by the Korea Meteorological Administration (KMA). In addition, for the future simulation, the Fifth-Generation NCAR/Penn State Mesoscale Model (MM5) coupling with atmosphere-ocean circulation model (ECHO-G) provided the future climatic data under the SRES (Special Report on Emission Scenario of IPCC) A1B scenarios. This study predicted the changes in vegetation distribution by climate change, and it analyzed the spatial and temporal variation of the Net Primary Production (NPP) and Soil Carbon Storage (SCS) using the MC1 model simulations. The vulnerability assessment of forest ecosystem can be divided into two categories; 1) the vulnerability of vegetation distribution and 2) the vulnerability of forest ecosystem function, such as the NPP and SCS. In addition, the sensitivity and adaption capacity were evaluated for each category. As results of the vulnerability assessment, relatively vulnerable areas were situated in the western coastal part and south eastern inland of Korea. Based on the spatial variation in vulnerability, we could suggest that the central and local governments need to prepare concentrated adaptation strategies for climate change based on the vulnerability assessment.
\end{abstract}

Keywords: climate change, forest ecosystem, vulnerability, MC1 model, Dynamic Global Vegetation Model

\section{INTRODUCTION}

According to the Intergovernmental Panel on Climate Change (IPCC), mean annual global temperature has been inclined by $0.744^{\circ} \mathrm{C}$ over the past 100 years, and it may be increased by $1.1-6.4^{\circ} \mathrm{C}$ in the future $2090 \mathrm{~s}$ (IPCC, 2007a). With the recent global warming, the IPCC (2007b) has considered that the climate change effect on forest ecosystem is one of major issues. The forest vegetation plays an important role in climate processes by its contribution to heat and moisture fluxes throughout the ecosystem. Therefore, it is important to evaluate the changes in forest ecosystem resulting from cli- mate change (ARris and EAGLeson, 1989; OHSAWA, 1993; MATSUi et al., 2004a; 2004b; LAURENT et al., 2004; HoRIKAWA, 2009). Previously, many studies on dynamic global vegetation models (DGVMs) were conducted to understand the climate change effects on the ecosystem (Prentice et al., 1992; Lenihan and NeILSON, 1993; BRZEZIECKI, 1995; CAO and WOODWARD, 1998; OSBORNE et al., 2000; BACHELET et al., 2001; WATANABE et al., 2004). The DGVMs simulate the changes in potential distribution of vegetation and its associated biogeochemical and/or hydrological fluxes due to climate change. The DGVMs simulate the annual or monthly dynamics of ecosystem processes. Their temporal and spatial resolutions depend on the time series of climate data and the given characteristics of latitude,
Corresponding author: Woo-Kyun Lee

E-mail: leewk@korea.ac.kr

${ }^{* 1}$ Department of Environmental Science and Ecological Engineering, Korea University, Seoul, 136-713, Korea
*2D Department of Climatic Environment, Graduate School of Life and Environmental Science, Korea University, Seoul, 136-713, Korea

${ }^{* 3}$ Korea Forest Research Institute, Seoul, 130-712, Korea 
topography, and soil data, respectively (BACHELET et al., 2001). Especially, United States Department of Agriculture (USDA) has developed the MAPSS-CENTURY (MC1) model to assess the climate change effects on the ecosystem of California, USA (LeniHAN et al., 2003; 2008). Also, in China, the Carbon Exchange between Vegetation, Soil, and Atmosphere (CEVSA) model predicted the potential vegetation distribution changes due to climate change ( $\mathrm{YU}$ et al., 2006).

Many researchers have tried to apply previous DGVMs, such as the Holdridge (KIM and LEE, 2006), CEVSA (LEE et al., 2007a), and MC1 (CHOI et al., 2009a), to assess the vulnerability of Korean forest ecosystem using the past and future climatic data, even though there were no national vegetation models in Korea (KIM et al., 2008). Practically, these models have limitations to provide accurate results for the regional scale of Korea, because most of them were designed and tested at the global or the continental scale, and Korea has more heterogeneous topography and climate, compared to global level (LEE et al., 2007a; KIM et al., 2009; CHOI et al., 2009a). However, due to the simple and clear processes of the MC1 model and CEVSA model, it is possible to use Geographic Information System (GIS) application and understand the sub-modules related to ecosystem mechanisms. In other words, these models are suitable to scrutinize the ecosystem vulnerability to climate change (BACHELET et al., 2001; Yu et al., 2006).

To assess the vulnerability of forest ecosystem to climate change, it requires several of information. Also, the indicators in vulnerability assessment should be comprehensive for each component of the forest ecosystem. The mechanisms of sensitivity and adaptation capacity are not completely clarified and it is hard to quantify the effect of each indicator on the vulnerability of forest ecosystem. However, principal component analysis (PCA) can be applied for vulnerability assessment, which compounds the related indicators and produces the newly synthetic indicators (HAN et al., 2006). According to LENIHAN et al. (2008), the MC1 can simulate the potential vegetation distribution, Net Primary Production (NPP) and Soil Carbon Storage (SCS). Also, it can assess the vulnerability of forest ecosystem due to climate change from the understanding of the sensitivity and adaptation capacity, related to the ecosystem structure, i.e. potential distribution, and the function, i.e. NPP and SCS.

For last three decades, the forest management policy pursues the sustainable management in Korea. Recently, corresponding to United Nations Framework Convention on Climate Change (UNFCCC), Korean government has prepared a master plan to expand the forest as a source of carbon sinks, and have constructed related statistical database. Moreover, for more effective conservation and management of the forest ecosystem, it is important to have the systemic monitoring and to designate the long-term ecological research area and special protection area (HAN et al., 2007). In other words, the climate change assessment of vulnerability using the DGVMs is aiming to minimize the negative effects of climate change on forest ecosystem, and it is required to predict the highly vulnerable area to enhance the adaptation capacity to climate change.

In this study, we analyzed the vulnerability of Korean forest ecosystem using the MAPSS-CENTURY (MC1) model based on the past and future climatic data. The assessment of vulnerability for forest ecosystem was divided into the two categories; the vulnerability of the vegetation distribution and forest ecosystem function, such as NPP and SCS. Also, it evaluated the sensitivity and adaptation capacity for each indicator.

\section{MATERIAL AND METHOD}

\section{The MC1 Model}

The $\mathrm{MCl}$ model is a DGVM to assess the climate change effects on ecosystem structure and function. It includes three modules, such as the biogeographic module - MAPSS (NEILSON, 1995), biogeochemistry module - modified CENTURY (PARTON et al., 1987), and fire module-MCFIRE (LENIHAN et al., 1998). This model can routinely generate simulations of tens to hundreds of years period on spatial data grids with cell sizes ranging from $900 \mathrm{~m}^{2}$ to about $2,500 \mathrm{~km}^{2}$ (BACHELET et al., 2004). As shown on Fig. 1, it simulates 1) the plant life-form and vegetation classes, 2) the movement of carbon, nitrogen, and water fluxes for ecosystem, and 3) fire disturbance, respectively (BACHELET et al., 2001). Also, it has two modes of equilibrium (static) and transient (dynamic) using climatic and soil information. It results in potential vegetation distribution using the life-form interpreter, and the NPP and SCS using the CENTURY model algorithm, respectively. The results of $\mathrm{MC1}$ model simulations were validated at the previous study of BACHELET et al. (2008). Compared to the observed data of NPP across the US, the $\mathrm{MC1}$ model results were fairly reasonable to be verified, even though it provided over and/or under-estimated results for some study sites. In this study, it used the default parameters and thresholds of the $\mathrm{MCl}$ model, even though, sometimes, it needs to optimize the model parameters when we apply the DGVMs to simulate the smaller region, such as Korea.

\section{Study Area and Data Preparation}

The study area was located in South Korea, $124^{\circ} 54^{\prime} \sim 131^{\circ} 06^{\prime}$ at longitude and $33^{\circ} 09^{\prime} \sim 38^{\circ} 45^{\prime}$ at latitude. Topographical characteristics of study area are shown in digital elevation model (Fig. 2a). The Taebaek Mountain Range elevates to over 1,500 $\mathrm{m}$ on the eastern side of Korea. From the Taebaek Mountain Range, the Sobaek Mountain Range runs from northern east to southern west. In the central zone, moderately high mountains dominate the landscape. Elevations are generally low, because these mountain ranges have been subjected to long-term erosion with relatively stable tectonic movements (NATIONAL 


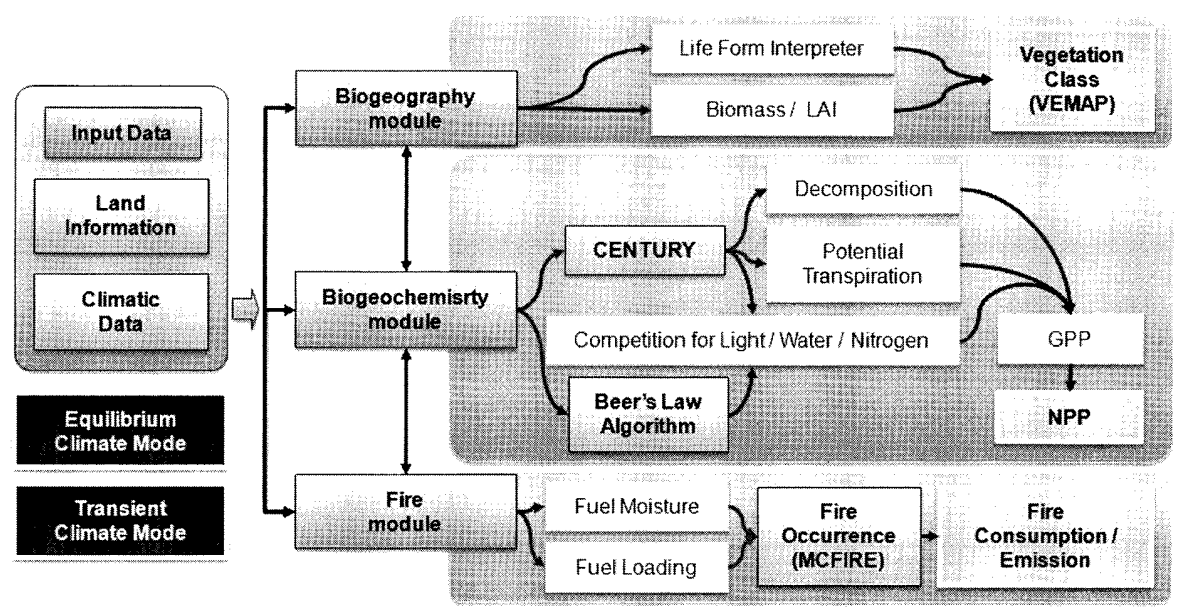

Fig. 1 The structure of the MC1 model source: BACHELET et al. (2001).

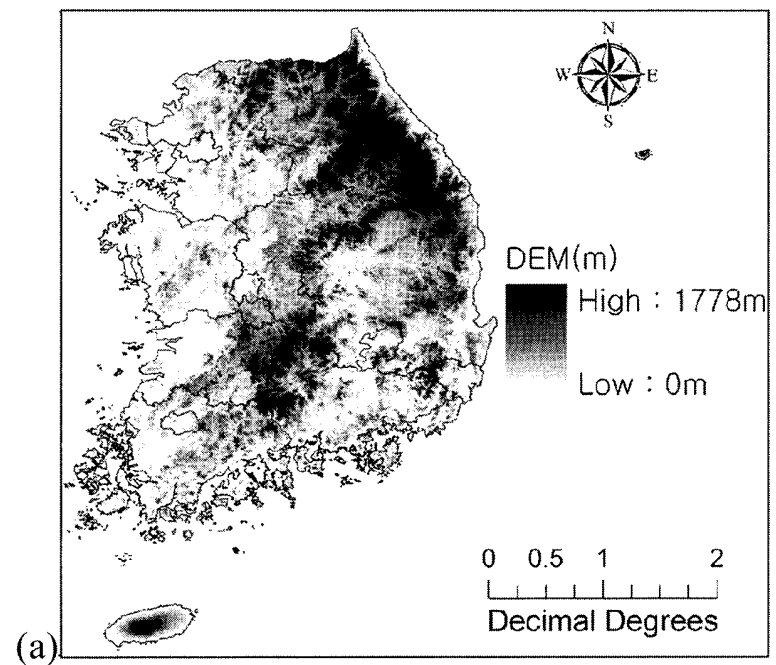

(b)

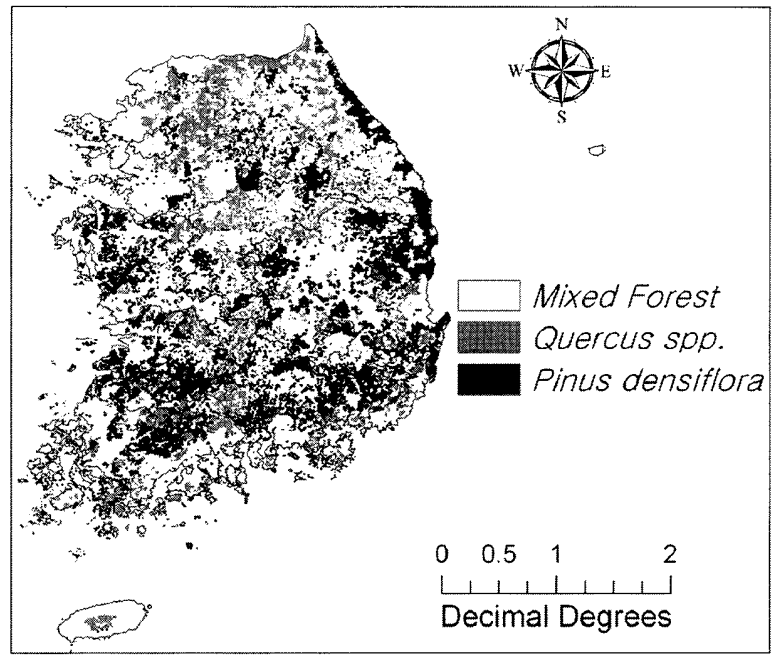

Fig. 2 (a) The Digital Elevation Model of Korea derived from National Geographic Information Institute and (b) the Actual forest type map from Korean Forest Service

Geographic Information Institute, 2007). As shown in Fig. 2b, evergreen needle-leaved forests (mainly Pinus densiflora) and deciduous broad-leaved forests (mainly Quercus spp.) occupy approximately $42 \%$ and $26 \%$ of the total forest area in 2008 , respectively (Korea Forest SeRvice, 2009). These species are major tree species in Korea and they are important in terms of ecological, economical, and socio-cultural values (LEE et al., 2006).

For the overall simulations, the MC1 needed two categories of input data, such as climatic and ancillary data. In terms of climatic dataset, seven climatic factors were needed to be prepared; they were cumulative precipitation, monthly mean temperature, mean daily maximum and minimum temperature, vapor pressure, wind speed, and solar radiation. Ancillary dataset included general geographical information, such as elevation, latitude, absolute area, and soil information, such as soil bulk density, soil texture, mineral depth, and rock fragment.

The temporal ranges of this study were assigned into three periods of 1) the past (1971-2000), 2) near future (2021-2050), and 3) far future (2071-2100). Korea Meteorological Administration (KMA) provided climatic data obtained by 75 weather stations across South Korea for the past years between 1971 and 2000 . These data were interpolated with Inverse Distance Squared Weighting (IDSW), one of the spatial statistic methods, regarding the absolute temperature lapse rate by altitude (LEE $e t$ al., 2007b). In addition, the anomalies of the future climatic data were predicted by the Fifth-Generation NCAR / Penn State Mesoscale Model (MM5) model coupling with atmosphereocean circulation model (ECHO-G) by A1B scenario (Special Report on Emission Scenario of IPCC) from National Institute of Meteorological Research (NIMR) in $0.2432^{\circ}$ (about $27 \mathrm{~km}$ ) of 
grid size (MIN et al., 2006; CHA et al., 2007). To construct the ancillary data, the elevation, latitude, and absolute area data were achieved from the digital map of the National Geographic Information Institute (NGII). Also, soil information, i.e. soil bulk density, soil texture, mineral depth, and rock fragment, were provided by the Food and Agriculture Organization (FAO) and International Soil Reference and Information Centre (ISRIC). These datasets were rescaled to fit on $0.01^{\circ}$ (about $1 \mathrm{~km}$ ) spatial resolution in the World Geodetic System (WGS-84) coordination system and applied to produce the future climate data based on the past climatic data (LEE et al., 2007b).

Assessment of Vulnerability

The vulnerability was defined as the range or scope of damage to nature or society system by climate change (IPCC, 2007b). This was estimated by relations between sensitivity and adaptation capacity as the indicators for the vulnerability assessment. The high sensitivity means the high vulnerability; reversely the low adaptation capacity means the high vulnerability (Yu et al., 2006; Yu, 2006; LEE et al., 2007a). This could be represented as following function (Eq. (1));

$$
V=S-A,
$$

where $V$ is the vulnerability, $S$ is the sensitivity, and $A$ is the adaptation capacity.

\section{Assessment of vulnerability-potential vegetation distribution}

In the MC1 model, the vulnerability of vegetation distribution and forest ecosystem functions, i.e. NPP and SCS, were estimated and integrated into the indicator of vulnerability of Korean forest. Each of them was estimated with sub indicators, such as the sensitivity and adaptation capacity in Eq. (1). In the vulnerability assessment of the potential vegetation distribution, the sensitivity to climate change was decided by the changing frequency of vegetation classes (or types) in each grid. For example, the changing frequency will increase, if there is once vegetation type change in a grid when the certain type of vegetation is not suitable for the provided climate condition (YU et al., 2006; YU, 2006; LeE et al., 2007a; HAN et al., 2007). The high changing frequency was assumed as the high sensitivity. The adaptation capacity could be estimated using the changing direction which was defined as two directions, such as positive $\left(^{+}\right)$and negative (-) direction (Yu et al., 2006; YU, 2006; LEE et al., 2007a; HAN et al., 2007). The positive changing was assumed to array from the mixed forest to the broad-leaved and needle-leaved forest in terms of maintenance of species diversity, because the needle-leaved forest has been reported to be likely to reduce the area by increase of temperature (KoNG, 2005; KIM and LEE, 2006). The positive changing was assumed to be the high adaptation.
Assessment of vulnerability-forest ecosystem function (NPP and SCS)

According to the assessment of vulnerability for the forest ecosystem function variables, such as the NPP and SCS, the sensitivity and adaptation were respectively described as the variability and changing trend (Yu et al., 2006; LEE et al., 2007a; HAN et al., 2007). The variability of forest ecosystem functions was estimated with the average values for the study period and whole period (1970-2100). The variability of each period implied as the differences between the values of study year and the average value for whole simulation term. It was described below (Eq. (2));

$$
D_{n}=\frac{\sum_{i=1}^{j}\left|V_{n i}-\overline{V_{n}}\right|}{\overline{V_{n}}},
$$

where $D$ is the variability of forest ecosystem functions for whole period (years), $V_{i}$ is the value of forest ecosystem function variable in study year $i, \bar{V}$ is the average value of the forest ecosystem function variable for whole period (years), and $n$ is a grid of the study site.

The adaptation capacity of forest ecosystem functions was estimated with the change trend of variability of forest ecosystem function variables, such as the NPP and SCS (YU et al., 2006; Yu, 2006; LEE et al., 2007a; HAN et al., 2007). Decreasing of the trend of variability means that the system is apt to be stabled to climate change, which can be described as the more adaptive (Eq. (3)). On the other hand, the increase of the trend means the forest ecosystem function variables were less stable and much more vulnerable to climate change. The trend of the forest ecosystem annual variability was represented as the slope of the linear trend lines fitting to the variability of the forest ecosystem functions in the study period ( $\mathrm{YU}$ et al., 2006; YU, 2006; LEE et al., 2007a; HAN et al., 2007).

$$
Y=a X+b
$$

where $Y$ is the variability of the study period, $X$ is the study period, and $a$ is the change trend of forest ecosystem function variables.

As shown in Fig. 3, this method can explain the sensitivity and adaptation capacity of forest ecosystem function. For example, in comparison of two test sites, such as A (Fig. 3a) and B (Fig. 3b), we assumed that a temporary variable of ecosystem function was simulated for 25 years (Hypothetical period). The average values were assumed as 18.6 and 18.24 for the site $\mathrm{A}$ and $\mathrm{B}$, respectively. In terms of the sensitivity, the site $\mathrm{A}$ was more sensitive than the site B, because the site A (Fig. 3c) had the larger sum of differences between the values for each year and the average for whole years, compared to the site B (Fig. $3 d)$. On the other hands, in terms of the adaptation capacity, the site $\mathrm{A}$ was more adaptive than the site $\mathrm{B}$, because the variability trend (slope) of site A (Fig. 3e) was negative (-0.0015: 
(a)
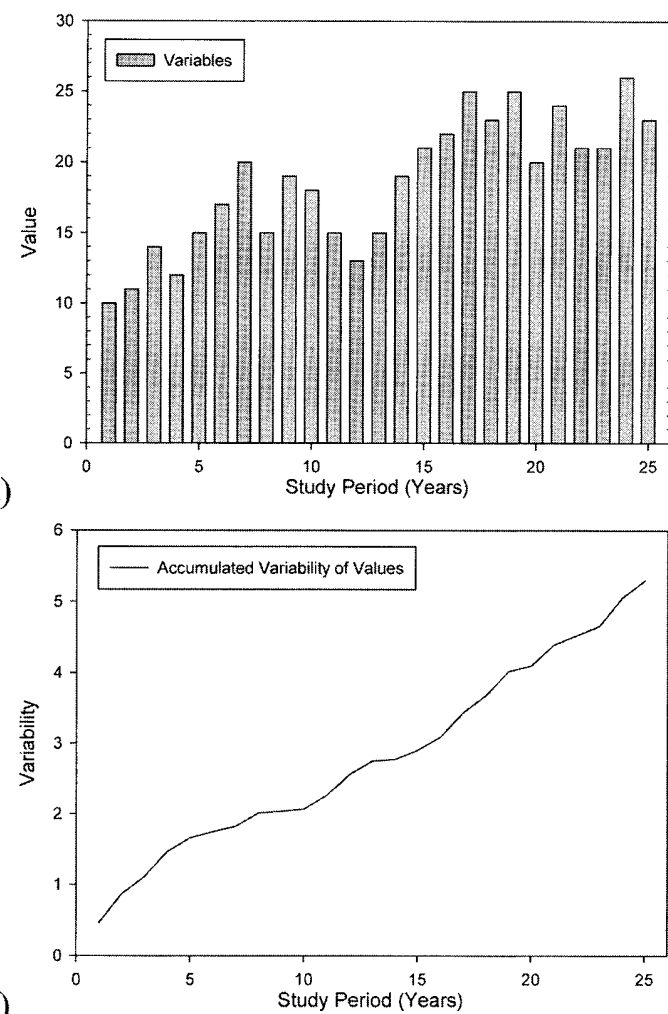

(c)

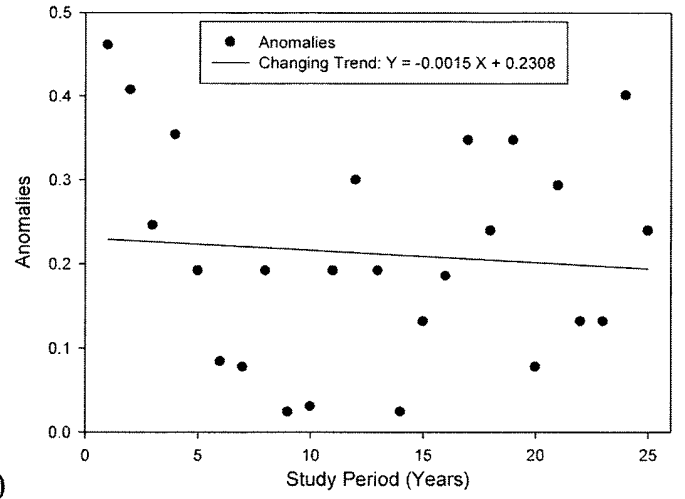

(e)

Fig. 3 Examples of sensitivity and adaptation capacity for a temporary variable of ecosystem function

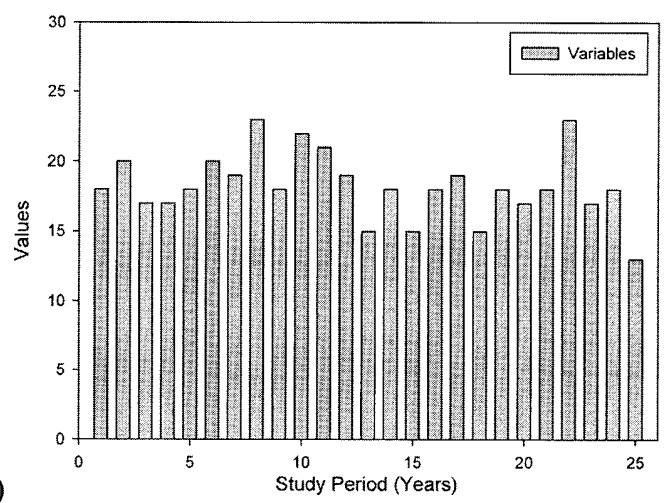

(b)

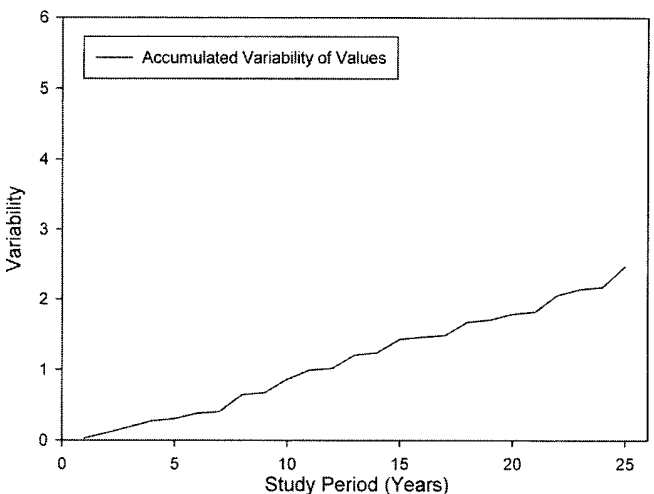

(d)

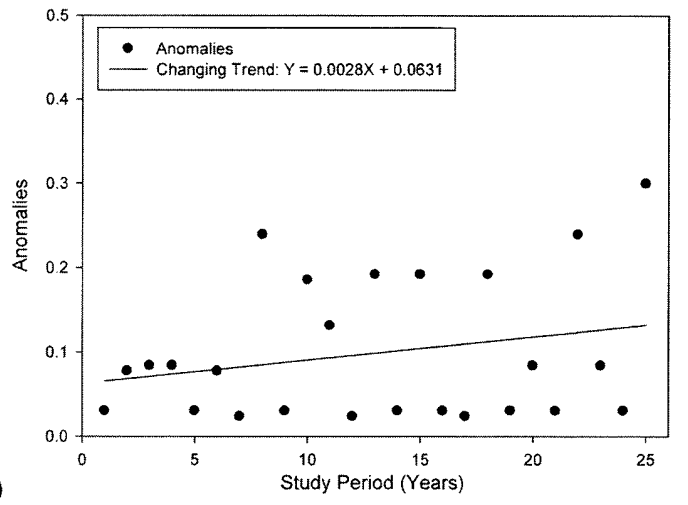

decrease of the variability for each year) and the trend of site $\mathrm{B}$ (Fig. 3f) was positive $(0.0028$ : increase of the variability for each year).

Integrated vulnerability of forest ecosystem distribution and function

To assess the vulnerability of Korean forest ecosystem, using the above indicators, the overall vulnerability of forest ecosystem was assessed by integrated indices, e.g. the vulnerability of both forest ecosystem distribution and functions. In the integration of indicators, we normalized the values of vulnerability for forest ecosystem distribution and forest ecosystem function (Eqs. (4) and (5)). In this study, we classified the vulnerability, sensitivity, and adaptation capacity into five categories, depending on their normalized ranges, such as "very high: 0.8-1.0", "high: 0.6-0.8", "moderate 0.4-0.6", "low: 0.2-0.4", and "very low: $0.0-0.2$ ". Also, the vulnerability of forest ecosystem was assessed with Principal Component Analysis (PCA) to calculate the degree of vulnerability (Table 1).

$$
{ }_{n} V=\frac{X-X_{m n}}{X_{m x}-X_{m n}}
$$

where ${ }_{n} V$ is the normalized vulnerability, $X$ is the estimated vulnerability, $X_{m n}$ is the minimum value of vulnerability, and $X_{m x}$ is the maximum value of vulnerability. 
Table 1 The scheme of vulnerability assessment of forest ecosystem

\begin{tabular}{|c|c|c|c|c|}
\hline Catego & es of vulnerability & Indicators & Sub-indicators & Description \\
\hline \multirow{6}{*}{$\begin{array}{c}\text { Forest } \\
\text { Ecosystem } \\
\text { Vulnerability }\end{array}$} & Vulnerability of & 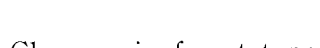 & Changing frequency & Sensitivity \\
\hline & vegetation distribution & Changes in torest type & Changing trend & Adaptability \\
\hline & \multirow{4}{*}{$\begin{array}{l}\text { Vulnerability of forest } \\
\text { ecosystem function }\end{array}$} & \multirow{2}{*}{ NPP } & Variability & Sensitivity \\
\hline & & & Trend of variability & Adaptability \\
\hline & & \multirow{2}{*}{ SCS } & Variability & Sensitivity \\
\hline & & & Trend of variability & Adaptability \\
\hline
\end{tabular}

${ }^{*}$ From the assessment process of $\mathrm{YU}$ et al. (2006).

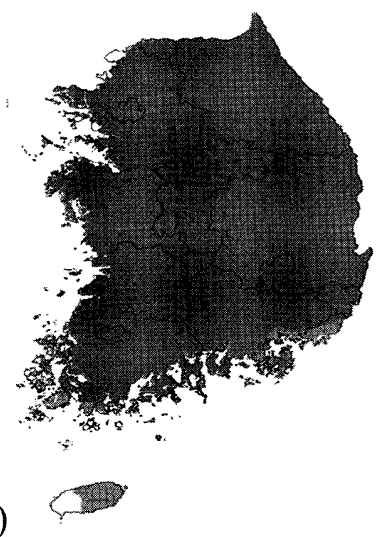

(a)

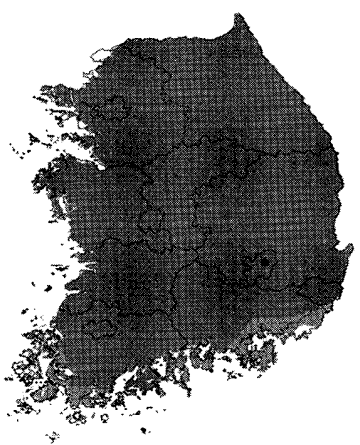

(b)

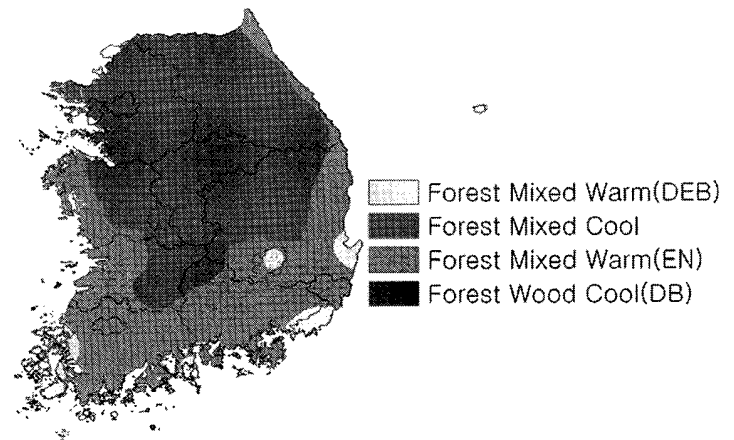

(c) (c)

Fig. 4 (a) the MC1 Simulation of the potential vegetation distribution of past (1971-2000), (b) near future (2021-2050), and (c) far future (2071-2100)

"EN: Evergreen Needle-leaved dominant; "DEB: Deciduous and Evergreen Broad-leaved dominant; "'DB: Deciduous Broad-leaved dominant.

Table 2 Proportion of potential vegetation distribution in area $\left(\mathrm{km}^{2}\right)$ and ratio (\%)

\begin{tabular}{crrr}
\hline Forest types & \multicolumn{1}{c}{ Past } & Near future & Far future \\
\hline Cool mixed forest & $* * * 95,214(96.06)$ & $92,351(93.18)$ & $55,117(55.61)$ \\
"Warm mixed forest (EN) & $3,252(3.28)$ & $5,549(5.60)$ & $38,634(38.98)$ \\
${ }^{*}$ Warm mixed forest (DEB) & $648(0.65)$ & $1,140(1.15)$ & $5,348(5.40)$ \\
${ }^{* * *}$ Forest hard wood cool (DB) & $1(0.00)$ & $75(0.07)$ & $16(0.02)$ \\
\hline Total & $99,115(100.00)$ & $99,115(100.00)$ & $99,115(100.00)$ \\
\hline
\end{tabular}

'EN: Evergreen Needle-leaved dominant; "DEB: Deciduous and Evergreen Broad-leaved dominant; "'DB: Deciduous Broad-leaved dominant; "'."Area in $\mathrm{km}^{2}$ (Ratio in \%).

Table 3 Changing frequency of each period in area $\left(\mathrm{km}^{2}\right)$ and ratio $(\%)$

\begin{tabular}{ccc}
\hline Changing frequency & From past to near future & From near future to far future \\
\hline Changed & $* 3,354(3.38)$ & $40,150(40.51)$ \\
Unchanged & $95,761(96.62)$ & $58,965(59.49)$ \\
\hline Total & $99,115(100.00)$ & $99,115(100.00)$ \\
\hline
\end{tabular}

Area in $\mathrm{km}^{2}$ (Ratio in \%). 


$$
{ }_{n} V_{E}={ }_{n} V_{D}+{ }_{n} V_{F},
$$

where ${ }_{n} V_{E}$ is the normalized forest ecosystem vulnerability, ${ }_{n} V_{D}$ is the normalized vulnerability of the forest ecosystem distribution, and ${ }_{n} V_{F}$ is the normalized vulnerability of the forest ecosystem function.

\section{RESULTS AND DISCUSSION}

Vulnerability of the Vegetation Distribution

\section{Potential vegetation distribution of past and future}

Fig. 4 depicts the simulated potential vegetation distribution of past (1971-2000), near future (2021-2050), and far future (2071-2100) using the MC1 model.

As results of the predicted potential vegetation distribution of past years (1971-2000), Korean ecosystem was mostly occupied by the cool mixed forest, the needle-leaved dominant (EN) warm mixed forest, and the broad-leaved dominant (DEB) warm mixed forest, and their proportions were $96.06 \%, 3.28 \%$, and $0.65 \%$, respectively. The cool mixed forests were occupying the most part of Korea and the EN warm mixed forest was existed in southern coast and the Jeju Island. In near future, the composition of forest types were $93.18 \%$ of the cool mixed forest, $5.60 \%$ of the EN warm mixed forest, and $1.15 \%$ of the DEB warm mixed forest. Compared to the past years, the EN warm mixed forests were expanding to northward, and the DEB warm mixed forests, which existed in only Jeju area, were appeared in southern metropolitan cities, such as Busan, Pohang, and Dae-Gu. In far future, there was no great change in overall composition of vegetation type, but distribution ratio was changed. The cool mixed forests were decreased down to $55.61 \%$ and the EN warm mixed forests were increased up to $38.98 \%$ (Table 2). This result was correspondent to the result of research by LEE et al. (2007a).

\section{Vulnerability of vegetation distribution}

To assess the vulnerability of vegetation distribution, it estimated the changing frequency and changing direction in terms of sensitivity and adaptability, respectively. As results of the sensitivity estimation for vegetation distribution, the future climate would not provide the suitable climatic condition for vegetations existed in the past years (Table 3 ), and $3.38 \%$ of the study area was exposed to be changed from past to near future. Also, there were vegetation composition changes in $40.51 \%$ of area from near future to far future. As the integrated changing frequencies above, the sensitivity of whole years (1971-2100) was derived in Table 3 and Fig. 5b.

From the results of predicting adaptation capacity of vegetation distribution, $3.38 \%$ of study area was likely to change to negative (-) direction from past to near future and $40.43 \%$ was changed to negative direction from near future to far future. Especially, some of region (1.30\%) will be exposed to two steps of negative direction $(-2)$ - from the cool mixed to the DEB

Table 4 Changing direction of each period in area $\left(\mathrm{km}^{2}\right)$ and ratio (\%)

\begin{tabular}{ccc}
\hline Changing direction & From past to near future & From near future to far future \\
\hline Positive direction $(+1)$ & - & $73(0.07)$ \\
No changes & $* 95,761(96.62)$ & $58,965(59.49)$ \\
Negative direction $(-1)$ & $3,279(3.31)$ & $38,771(39.12)$ \\
Negative direction $(-2)$ & $1(0.00)$ & $1,292(1.30)$ \\
Negative direction $(-3)$ & $74(0.07)$ & $14(0.01)$ \\
\hline Total & $99,115(100.00)$ & $99,115(100.00)$ \\
\hline
\end{tabular}

'Area in $\mathrm{km}^{2}$ (Ratio in \%).

Table 5 Sensitivity, adaptation capacity, and vulnerability of vegetation distribution in area $\left(\mathrm{km}^{2}\right)$ and ratio (\%)

\begin{tabular}{cccc}
\hline Sensitivity Adaptation Capacity Vulnerability & Changing frequency & Changing direction & Overall vulnerability \\
\hline Very High $(0.8 \sim 1.0)$ & ${ }^{*} 1,174(1,18)$ & $1(0.00)$ & $1,190(1.20)$ \\
High $(0.6 \sim 0.8)$ & - & $56,785(57.29)$ & $1,293(1.30)$ \\
Moderate $(0.4 \sim 0.6)$ & $41,156(41.52)$ & $39,846(40.20)$ & $39,846(40.20)$ \\
Low $(0.2 \sim 0.4)$ & - & $2,467(2.49)$ & - \\
Very Low $(0.0 \sim 0.2)$ & $56,785(57.29)$ & $16(0.02)$ & $56,786(57.29)$ \\
\hline Total & $99,115(100.00)$ & $99,115(100.00)$ & $99,115(100.00)$ \\
\hline
\end{tabular}

-Area in $\mathrm{km}^{2}$ (Ratio in \%). 
(a)

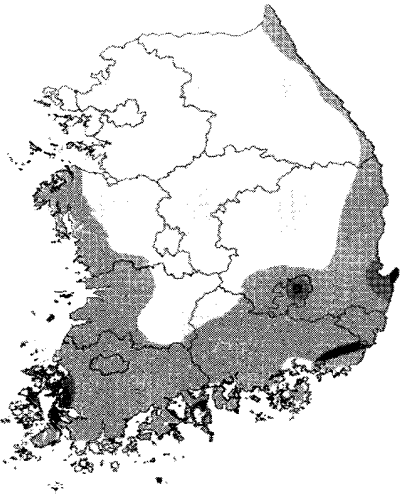

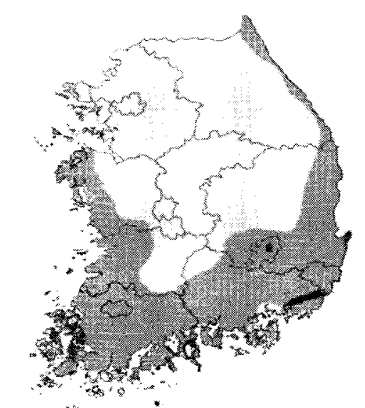

(b)

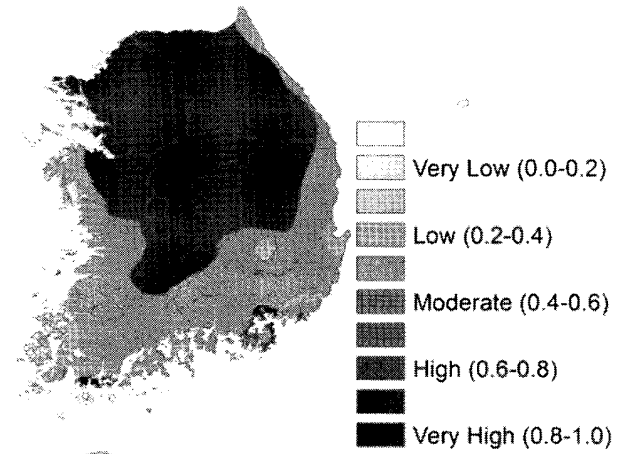

(c)

Fig. 5 (a) Vulnerability of vegetation distribution, (b) Sensitivity, and (c) Adaptation Capacity of vegetation distribution Vulnerability of vegetation distribution $=$ Sensitivity (Changing frequency) - Adaptation Capacity (Changing direction).

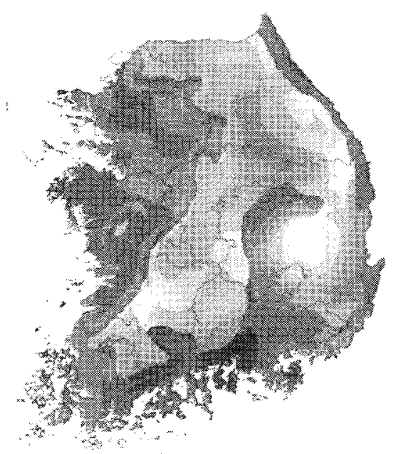

(a)

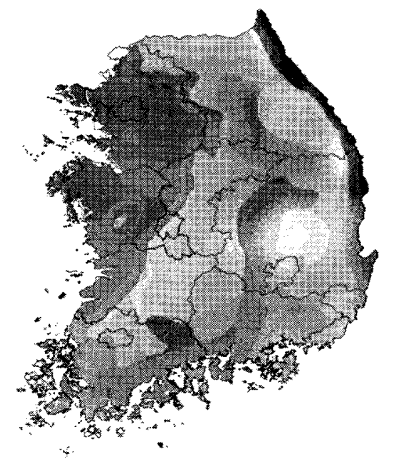

(d)

(e)

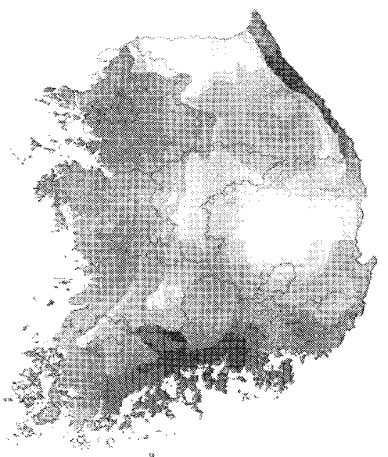

(b)

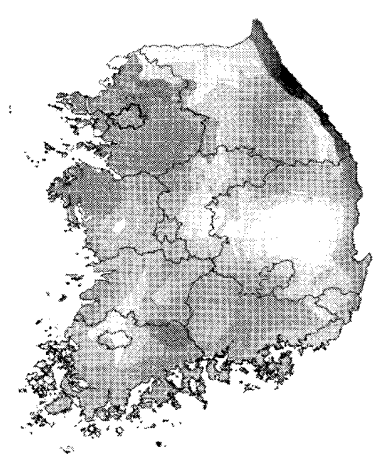

(1) (f)

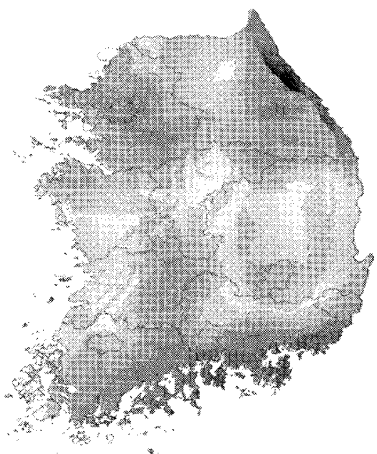

(c)
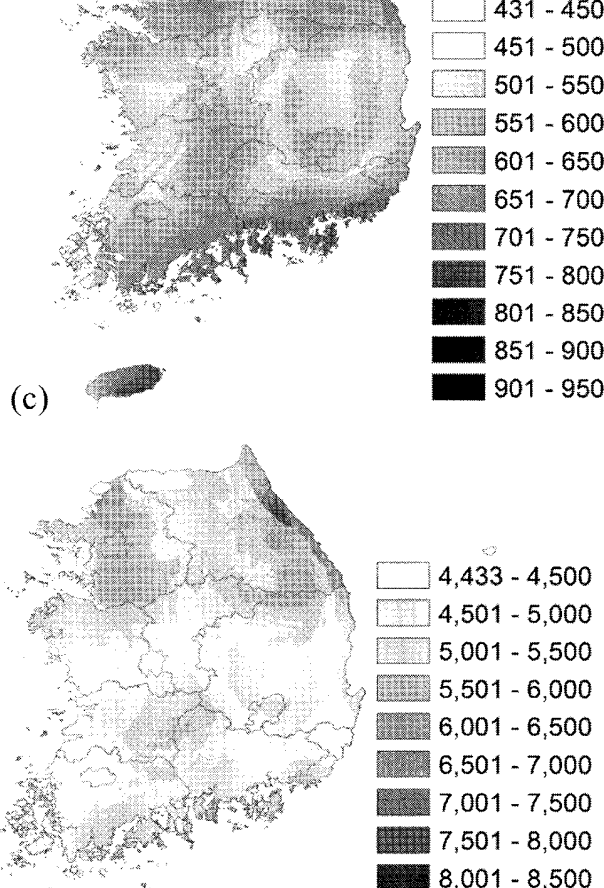

$4,433-4,500$

$4,501-5,000$

$5,001-5,500$

$5,501-6,000$

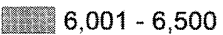

$6,501-7,000$

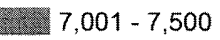

포페료 $7,501-8,000$

표 $8,001-8,500$

준 $801-9,000$

Fig. 6 (a) MC1 Simulated potential NPP distribution of past (1971-2000), (b) near future (2021-2050), and (c) far future (2071-2100), and (d) potential SCS distribution of past, (e) near future, and (f) far future 
Table 6 Variability and changing trend of NPP and SCS in area $\left(\mathrm{km}^{2}\right)$ and ratio (\%)

\begin{tabular}{ccccc}
\hline Sensitivity & \multicolumn{2}{c}{ Variability } & \multicolumn{2}{c}{ Changing trend } \\
\cline { 2 - 5 } Adaptation Capacity & NPP & SCS & NPP & SCS \\
\hline Very High $(0.8 \sim 1.0)$ & - & - & $1,252(1.26)$ & $2,067(2.09)$ \\
High $(0.6 \sim 0.8)$ & - & $132(0.13)$ & $3,878(3.91)$ & $16,746(16.90)$ \\
Moderate $(0.4 \sim 0.6)$ & $2,271(2.29)$ & $19,020(19.19)$ & $50,921(51.38)$ & $55,202(55.69)$ \\
Low $(0.2 \sim 0.4)$ & $30,695(30.97)$ & $62,231(62.79)$ & $41,023(41.39)$ & $24,205(24.42)$ \\
Very Low $(0.0 \sim 0.2)$ & $66,149(66.74)$ & $17,732(17.89)$ & $2,041(2.06)$ & $895(0.90)$ \\
\hline Total & $99,115(100.00)$ & $99,115(100.00)$ & $99,115(100.00)$ & $99,115(100.00)$ \\
\hline
\end{tabular}

"Area in $\mathrm{km}^{2}$ (Ratio in \%).

warm mixed forest (Table 4). From the changing directions, the adaptation capacity of whole year (1971-2100) was estimated in table 5 and Fig. $5 \mathrm{c}$.

The vulnerability of vegetation distribution can be assessed by the integration of the sensitivity and adaptation capacity. The higher changing frequency and the negative trend of changing direction are comprehended as the high vulnerability of vegetation distribution. As results of the integration of above results, some part of southern inland area and western and eastern coastal areas (2.50\% of study area) were exposed to the "Very high" or "High" vulnerability (Fig. 5a and Table 5). It is assumed that the mean monthly temperatures would increase by $4.1-4.6^{\circ} \mathrm{C}$ in far future and the accumulated precipitation in growing season would be 1.5-2.8 times higher in far future than in past (1971-2000). However, other study area was exposed to the "Very low" vulnerability (57.29\%) and the "Moderate" vulnerability (40.20\%) of vegetation distribution.

Vulnerability of Forest Ecosystem Function

\section{Potential NPP and SCS distribution of past and future}

Fig. 6 depicted the simulated NPP and SCS distribution in past, near future, and far future. The potential vegetation production and carbon storage in soil were simulated by the $\mathrm{MCl}$ using soil temperature and moisture derived from the climatic information, and nitrogen availability derived from the soil information. The NPP of past was ranged from 430.93 to 796.28 $\mathrm{gC} \cdot \mathrm{m}^{-2} \cdot \mathrm{yr}^{-1}$ and the average was 647.90 (std. dev. 73.99) $\mathrm{gC} \cdot \mathrm{m}^{-2}$. $\mathrm{yr}^{-1}$. Compared to the past, the range of the overall estimated NPP would be changed in near future $\left(376.33-827.27 \mathrm{gC} \cdot \mathrm{m}^{-2} \cdot \mathrm{yr}^{-1}\right)$ and far future $\left(498.53-901.59 \mathrm{gC} \cdot \mathrm{m}^{-2} \cdot \mathrm{yr}^{-1}\right)$. Also, the average of NPP would decrease to $609.02 \mathrm{gC} \cdot \mathrm{m}^{-2} \cdot \mathrm{yr}^{-1}$ in near future and $599.70 \mathrm{gC} \cdot \mathrm{m}^{-2} \cdot \mathrm{yr}^{-1}$ in far future. On the other hands, the average of SCS in past was $6,810.5$ (std. dev. 784.0$) \mathrm{gC} \cdot \mathrm{m}^{-2}$. The SCS was ranged from $4,720.5$ to $9,478.2 \mathrm{gC} \cdot \mathrm{m}^{-2}$ in past. As similar as the NPP, the average value of the SCS would decrease to $6,008.8$ $\mathrm{gC} \cdot \mathrm{m}^{-2}$ in near future (range: $4,432.0-9,042.4 \mathrm{gC} \cdot \mathrm{m}^{-2}$ ) and $5,154.5$ $\mathrm{gC} \cdot \mathrm{m}^{-2}$ in far future (range: $3,930.5-8,493.9 \mathrm{gC} \cdot \mathrm{m}^{-2}$ ) due to climate change.

\section{J. For. Plann. 16: 149-161 (2011)}

\section{Vulnerability of forest ecosystem function}

To assess the vulnerability of forest ecosystem function, it estimated variability and changing trend of the NPP and SCS in terms of sensitivity and adaptation capacity, respectively. As results of sensitivity estimation for forest ecosystem function, overall variability of the NPP and SCS was relatively low. More than $80 \%$ of study area was classified as the "Low" or "Very low" of variability (e.g. $97.71 \%$ for the NPP and $80.68 \%$ for the $\mathrm{SCS})$. In other words, the forest ecosystem functions did not respond to climate change sensitively, compared to the sensitivity of vegetation distribution. Conversely, in terms of adaptation capacity, the change trends of variability for the NPP and SCS were likely to be "Moderate" or "Low" adaptability (e.g. $92.77 \%$ for the NPP and $80.11 \%$ for the SCS) (Table 6).

The vulnerability of forest ecosystem function could be assessed by the integration of sensitivity and adaptation capacity of the NPP and SCS. The higher variability and the positive changing trend were comprehended as the high vulnerability of forest ecosystem function. As results of integration of above results, western coastal and inland areas were exposed to the "Very high" or "High" vulnerability $(0.92 \%$ of study area). However, $85.14 \%$ of study area was exposed to the "Very low" or "Low" vulnerability (Fig. 7 and Table 7). This is assumed that mineral depth of the vulnerable area was deeper than $40 \mathrm{~cm}$ and the bulk density of the vulnerable area was greater than $1.09 \mathrm{~g} / \mathrm{cm}^{3}$, compared to other area. The characteristics could be combined with precipitation and they are related to soil moisture and hydrological values which highly affect on the NPP and SCS (BACHELET et al., 2001).

\section{Vulnerability of Forest Ecosystem}

With the integration of vulnerability for vegetation distribution and forest ecosystem function, the overall vulnerability of forest ecosystem was evaluated for forest ecosystem in Korea. As shown Fig. 8 and table $8,50.61 \%$ of Korea was exposed to the "Very low" vulnerability of forest ecosystem. However, some part of Korean ecosystem would be exposed to the "Very high" or "High" vulnerability in southern west and east coastal area and southern east land area due to climate change 


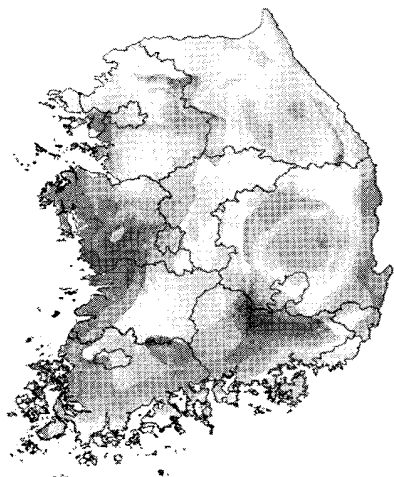

(a)

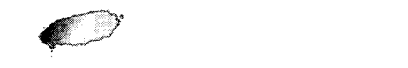

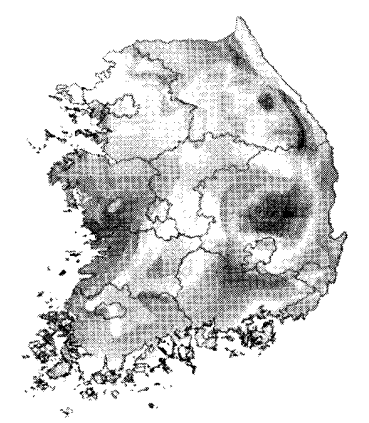

(b)

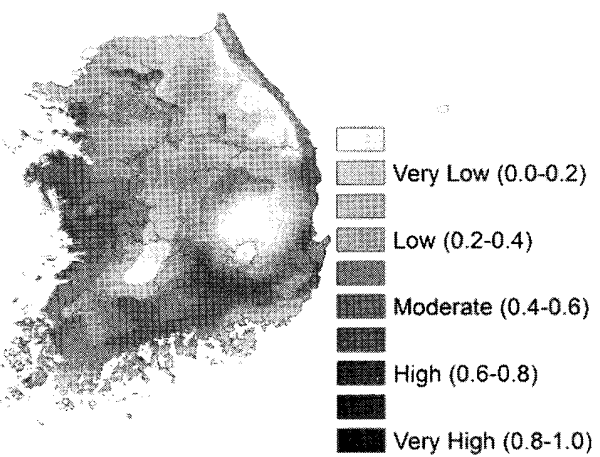

(c)

Very High (0.8-1.0)

Fig. 7 (a) Vulnerability of forest ecosystem function (NPP+SCS), (b) NPP and (c) SCS vulnerability ${ }^{*}$ Vulnerability of forest ecosystem function $=$ NPP vulnerability + SCS vulnerability.

Table 7 Vulnerability of forest ecosystem function - NPP and SCS in area $\left(\mathrm{km}^{2}\right)$ and ratio (\%)

\begin{tabular}{cccc}
\hline $\begin{array}{c}\text { Vulnerability of forest } \\
\text { ecosystem function }\end{array}$ & NPP & SCS & $\begin{array}{c}\text { Integrated NPP } \\
\text { and SCS }\end{array}$ \\
\hline Very High $(0.8 \sim 1.0)$ & ${ }^{*} 349(0.35)$ & $205(0.21)$ & $106(0.11)$ \\
High $(0.6 \sim 0.8)$ & $2,770(2.79)$ & $4,354(4.39)$ & $806(0.81)$ \\
Moderate $(0.4 \sim 0.6)$ & $15,416(15.55)$ & $37,637(37.97)$ & $13,817(13.94)$ \\
Low $(0.2 \sim 0.4)$ & $35,326(35.64)$ & $41,431(41.80)$ & $33,652(33.95)$ \\
Very Low $(0.0 \sim 0.2)$ & $45,254(45.66)$ & $15,488(15.63)$ & $50,734(51.19)$ \\
\hline Total & $99,115(100.00)$ & $99,115(100.00)$ & $99,115(100.00)$ \\
\hline
\end{tabular}

*Area in $\mathrm{km}^{2}$ (Ratio in \%).

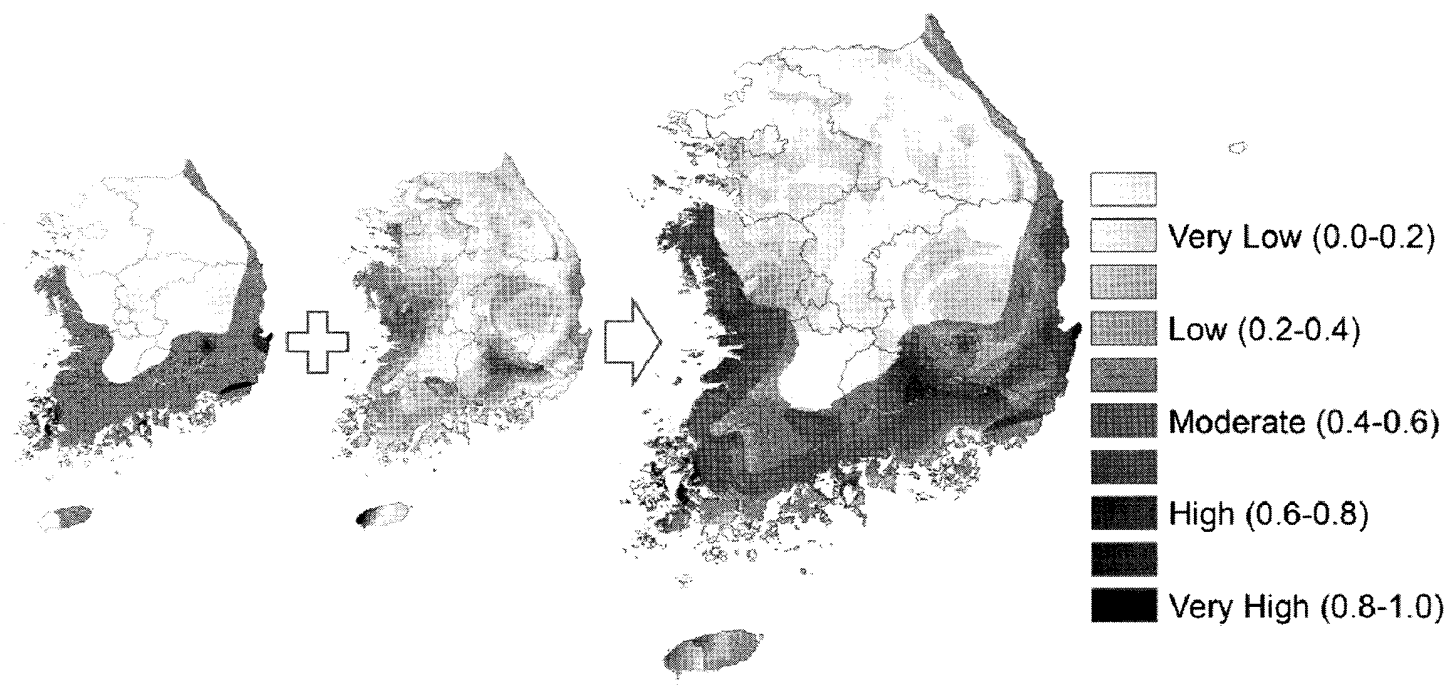

Fig. 8 Vulnerability of forest ecosystem

${ }^{*}$ Vulnerability of vegetation distribution + Vulnerability of forest ecosystem function $=$ Vulnerability of forest ecosystem. 
Table 8 Vulnerability of forest ecosystem in area $\left(\mathrm{km}^{2}\right)$ and ratio (\%)

\begin{tabular}{cc}
\hline Vulnerability & Overall vulnerability of forest ecosystem \\
\hline Very High $(0.8 \sim 1.0)$ & $603(0.61)$ \\
High $(0.6 \sim 0.8)$ & $11,011(11.11)$ \\
Moderate $(0.4 \sim 0.6)$ & $26,208(26.44)$ \\
Low $(0.2 \sim 0.4)$ & $11,129(11.23)$ \\
Very Low $(0.0 \sim 0.2)$ & $50,164(50.61)$ \\
\hline Total & $99,115(100.00)$ \\
\hline
\end{tabular}

'Area in $\mathrm{km}^{2}$ (Ratio in \%).

(11.72\% of study area). In this high vulnerable area, both vegetation distribution and forest ecosystem function were sensitive to climate change and were exposed to less adaptation capacity. The reasons of high vulnerability could be 1) the increase of monthly mean temperature and minimum temperature, i.e. two of threshold for life-form interpreter of the MC1 model, 2) the soil condition influencing the vegetation production and soil carbon storages (BACHELET et al, 2001), even though these reasons should be validated in future research.

The vulnerability of vegetation distribution was evaluated to be higher than that of forest ecosystem function in Korea. In the study of LEE et al. (2007a), the forest ecosystem was assessed with CEVSA model. They also resulted in relative high vulnerability of vegetation distribution, compared to the vulnerability of forest ecosystem function. However, the $\mathrm{MCl}$ model, as one of the DGVMs, has limitation that it cannot perfectly explain the relatively heterogeneous topography and micro-climate of Korea. Also, the MC1 performance for Korean ecosystem could not be validated with the field observed NPP and SCS data at the plot-scale. The vegetation and carbon dynamics are significantly affected by natural disturbance, such as fires, in the $\mathrm{MCl}$ run at the country scale, whereas carbon changes due to the fires are infrequent and difficult to quantify at the plot-scale (BACHELET et al., 2008). So, it could be discrepant between the model results and field measurements. In addition, the $\mathrm{MCl}$ model did not consider the direct anthropogenic effects on forest ecosystem. Therefore, the results of vulnerability assessment in this study needs to be supplemented by optimizing the previous models and developing Korea-specific vegetation model. To optimize and develop the Korea-specific model, it is required to apply the Warmth Index (YIM, 1977), mean minimum temperature of the coldest month (MTC), summer and winter precipitation (HoRIKAwA et al., 2007), and slope and direction of topography algorithms (LEE et al., 2006). Recently, CHOI et al. (2009b) have conducted on a study to predict vegetation distribution by climate change using the WI and MTC, and in further research, they will develop regional scale model related to terrestrial carbon fluxes. It would be one of useful complementary source for forest ecosystem vulnerability assessment.

\section{CONCLUSIONS}

This study analyzed the overall vulnerability of Korean forest ecosystem by the integrated assessment of vulnerability of both vegetation distribution and forest ecosystem function using the MAPSS-CENTURY (MC1) model based on the past and future climatic data. Korean ecosystem was mostly occupied by the cool mixed forest, the warm mixed forest (Evergreen Needle-leaved dominant: EN), and the warm mixed forest (Deciduous and Evergreen Broad-leaved dominant: DEB). Their proportions were $96.06 \%, 3.28 \%$, and $0.65 \%$, respectively. Southern inland area and western and eastern coastal areas (11.72\% of study area) were exposed to the very high or high vulnerability of forest ecosystem. Also, $61.84 \%$ of study areas have the "Very low" or "Low" vulnerability of forest ecosystem. Overall vulnerability of forest ecosystem in Korea was in the "Low" or "Moderate" level. However, Korean ecosystem would be exposed to the high vulnerability in southern west coastal area and southern east land area due to climate change. According to KONG (2005) and KIM and LEE (2006), in the high vulnerable area to climate change, the forest vegetations are easily exposed to the heat stress or drought and they are likely to die off due to the changes in forest climate region. Also, unsuitable environmental condition for forest growth and breeding would lead the reduction of forest production and the degradation of forest vegetation. Based on the spatial variation in vulnerability, we could suggest that the central and local governments need to prepare concentrated adaptation strategies for climate change based on the vulnerability assessment. However, these studies, using DGVMs, has limitation that it is difficult to consider the heterogeneous topography and micro-climate of Korea and the direct anthropogenic effects on forest ecosystem. Therefore, the results of vulnerability assessment in this study needs to be supplemented by optimizing the previous models and developing the Korea-specific vegetation model. 


\section{ACKNOWLEDGEMENTS}

This study was supported by the KFRI research project "Impact Assessment of Climate Change on Forest Ecosystem and Development of Adaptation Strategies (Project No: FE 0100-2009-01)."

\section{LITERATURE CITED}

ArRIS, L.L. and EAGLEson, P.S., (1989): Evidence of a physiological basis for the boreal-deciduous forest ecotone in North America. Vegetatio 82: 55-58

Bachelet, D., Lenihan, J.M., Daly, C., Neilson, R.P., Ojima, D. S. and PARTON, W.J., (2001): MC1: a dynamic vegetation model for estimating the distribution of vegetation and associated carbon, nutrients, and water. U.S. Department of Agriculture, Forest Service, Pacific Northwest Research Station. Technical documentation, version 1.0

Bachelet, D., Lenihan, J.M., Drapek, R. and Neilson, R., (2008): VEMAP vs VINCERA: A DGVM sensitivity to differences in climate scenarios. Global and Planetary Changes 64: 38-48

BrzeZIECKI, B., KiEnAST, F. and WildI, O., (1995): Modelling potential impacts of climate change on the spatial distribution of zonal forest communities in Switzerland. J. Veg. Sci. 6: $257-268$

CAO, M.K. and WoOdWard, F.I., (1998): Dynamic responses of terrestrial ecosystem carbon cycling to global climate change. Nature 393 (21): 249-252

Cha, Y.M., Lee, H.S., Moon, J.Y., Kwon, W.T. and Boo, K.O., (2007): Future climate projection over East Asia using ECHOG/S. Atmosphere 17 (1): $55-68$ (in Korean with English Abstract)

ChoI, S., Lee, W.K., KwaK, H.B. and KIm, S.R., (2009a): Predicting the vegetation distribution and terrestrial carbonfluxes using MC1 model. Proceedings of ESRI International User Conference 2009, San-Diego, USA. On-line Published. http://proceedings.esri.com/dvd/uc/2009/uc/papers/pap_ 1479.pdf

Chol, S., LeE, W.K. and Yoo, S., (2009b): Predicting forest cover and $\mathrm{CO}_{2}$ storage change by climate change in Korea. Proceedings of International Symposium on National Forest Inventory - Forest Resources Monitoring \& Climate Change, Kangwon, Korea: 119-120

HaN, W.J., KIM, J.E., LeE, J.T., NA, Y.E., KIM, M.H., BaE, D.H., Jung, I.W. and Hwang, J.H., (2005): Climate change impact assessment and development of adaptation strategies in Korea I. Korea Environment Institute: 212-234

HaN, W.J., Kim, J.E., LeE, J.T., Na, Y.E., KIm, M.H., BAE, D.H., Jung, I.W. and Hwang, J.H., (2006): Climate change impact assessment and development of adaptation strategies in Korea II. Korea Environment Institute: 227-252

Han, W.J., KIM, J.E., LEE, J.T., NA, Y.E., KIM, M.H., BaE, D.H., JuNG, I.W. and Hwang, J.H., (2007): Climate change impact assessment and development of adaptation strategies in Ko- rea III. Korea Environment Institute: 312-320

Horikawa, M., Tsuyama, I., Matsui, T., Kominami, Y. and TANAKA, N., (2009): Assessing the potential impacts of climate change on the alpine habitat suitability of Japanese stone pine (Pinus pumila). Landscape Ecol. 24: 115-128

IPCC, (2007a): In: Solomon, S., QIn, D., Manning, M., Chen, Z., Marquis, M., Averyt, K.B., Tignor, M. and Miller, H.L. (eds) Climate change 2007: the physical science basis. Contribution of working group I to the fourth assessment report of the intergovernmental panel on climate change. Cambridge University Press, Cambridge, UK: 1032

IPCC, (2007b): In: Parry, M.L., Canziani, O.F., Palutikof, J.P., Linden, P.J. and Hanson, C.E. (eds) Climate change 2007: impacts, adaptation and vulnerability. Contribution of work ing group II to the fourth assessment report of the intergovernmental panel on climate change. Cambridge University Press, Cambridge, UK: 976

KIM, J.U. and LEE, D.K., (2006): A study on the vulnerability assessment of forest vegetation using regional climate model. J. Korean Environ. Restoration Reveg. Tech. 9 (5): 3240 (in Korean with English Abstract)

KIM, S.N., LEE, W.K., Son, Y., CHO, Y., LEE. and M.S., (2009): Applicability of climate change impact assessment models to Korean forest. J. Korean For. Soc. 98(1): 33-48 (in Korean with English Abstract)

KonG, W.S., (2005): Selection of vulnerable indicator plants by global warming. Asia-Pacific J. Atm. Sci. 41 (2-1): 263-273

Korea Forest Service, (2009): Statistical yearbook of forestry, 2008. Korea Forest Service, Seoul, Chapter II, 30-32

Laurent, J. M., Bar-Hen, A., Françors, L., Ghislain, M. and CHEDDADI, R., (2004): Refining vegetation simulation models: From plant functional types to bioclimatic affinity groups of plants. J. Veg. Sci., 15: 739-746

Lee, C.S., Lee, W.K., Yoon, J.H. and SonG, C.C., (2006): Distribution pattern of Pinus desiflora and Quercus spp. stand in Korea using spatial statistics and GIS. J. Korean For. Soc. 95 (6): $663-671$

LeE, M.A., LeE, W.K., Son, Y., Cho, Y.S. and Song, C.C., KIM, T.M., YU, L., TAO, B., (2007a): Sensitivity and adaptability of vegetation and soil carbon storage to climate change with CEVSA model in Korea. Proc. A3 Foresight Program: 24

LeE, M.A., Lee, W.K., Song, C.C., LeE, J.H., Chol, H.A. and Kim, T.M., (2007b): Spatio-temporal change prediction and variability of temperature and precipitation. J. GIS Assoc. Korea $\mathbf{1 5}$ (3): 1-12 (in Korean with English Abstract)

Lenihan, J.M., Bachelet, D., Neilson, R.P. and DrapeK, R., (2008): Response of vegetation distribution, ecosystem productivity, and fire to climate change scenarios for California. Climatic Change 87 (1): S215-\$230

Lenihan, J.M., Daly, C., BACHElet, D. and NeILSON, R.P., (1998): Simulating broad-scale fire severity in a dynamic global vegetation model. Northwest Sci. 72 (2): 91-103

Lenihan, J.M., Drapek, R., BaChelet, D. and Neilson, R.P., (2003): Climate change effects of vegetation distribution, car- 
bon, and fire in California. Ecol. Appl. 13 (6): 1667-1681

Lenihan, J.M. and NeILson, R.P., (1993): A Rule-Based Vegetation Formation Model for Canada. J. Biogeogr. 20 (6): 615-628

Matsu, T., Yagihashi, T., Nakaya, T., Tanaka, N. and Taoda, H., (2004a): Climate controls on distribution of Fagus crenata forests in Japan. J. Veg. Sci. 15: 57-66

Matsui, T., Yagihashi, T., Nakaya, T., Taoda, H., Yoshinaga, S., Daimaru, H. and Tanaka, N., (2004b): Probability distributions, vulnerability and sensitivity in Fagus crenata forests following predicted climate changes in Japan. J. Veg. Sci. 15: $605-614$

Min, S.K., LegutKe, S., Hense, A., Cubasch, U., Kwon, W.T., $\mathrm{OH}$, J.H. and ScHLES, U., (2006): East Asian climate change in the 21st century as simulated by the coupled climate model ECHO-G under IPCC SRES scenarios. J. Meteor. Soc. Jpn. 82: 1187-1211

NATIONAL GEOGRAPHIC InFoRMATION InSTITUTE, (2007): The National Atlas of Korea 2007,[2007-12-01] Internet Service. http: //atlas.ngii.go.kr/english/explanation/natural_1_1.jsp (accessed on Feb. 15, 2010)

NeILSON, R.P., (1995): A model for predicting continental-scale vegetation distribution and water balance. Ecol. Appl. 5 (2): 362-385

OHSAWA, M., (1993): Latitudinal pattern of mountain vegetation zonation in southern and eastern Asia. J. Veg. Sci. 4: 13-18

Osborne, C.P., Mitchell, P.L., Sheehy, J. E. and Woodward,
F.I., (2000): Modelling the recent historical impacts of atmospheric $\mathrm{CO}_{2}$ and climate change on Mediterranean vegetation. Global Change Biol. 6: 445-458

Parton, W.J., Schimel, D.S., Cole, C.V., OJima, D.S., (1987): Analysis of factors controlling soil organic matter levels in Great Plains grasslands. Soil Sci. Soc. Am. J. 51: 1173-1179

Prentice, I.C., Cramer, W., Harrison, S.P., Leemans, R. and Monserud, R.A., Solomon, A.M., (1992): A global biome model based on plant physiology and dominance, soil properties and climate. J. Biogeogr. 19: 117-134

Watanabe, T., Yokozawa, M., Emori, S., TaKata, K., Sumdd, A. and HARA, T., (2004): Developing a multilayered integrated numerical model of surface physics-growing plants interaction (MINoSGI). Global Change Biol. 10: $963-982$

YIM, Y.J., (1977): Distribution of forest vegetation and climate in the Korean peninsula. III. Distribution of tree species along the thermal gradient. Jpn. J. Ecol. 27: 177-189

YU, L., (2006): Assessment the vulnerability of natural ecosystems to climatic change in China. Chinese Academy of Sciences. $\mathrm{Ph} . \mathrm{D}$. thesis (in Chinese)

Yu, L., CAO, M.K. and LI, K., (2006): Climate-induced changes in the vegetation pattern of China in the 21st century. Ecol. Res. 21: $912-919$

(Received 23 September 2009) (Accepted 10 June 2010) 